\title{
DIE STARKE
}

\section{Bibliographie der Weltliteratur}

\author{
von \\ Prof. Dr. Max Ulmann \\ Herausgegeben vom Institut für Ernährung \\ Potsdam-Rehbrücke \\ der Deutschen Akademie der Wissenschaften zu Berlin
}

\section{LIEFERUNG 14}

General-Schlagwortverzeichnis

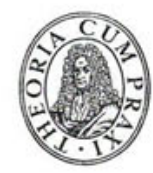

AKADEMIE-VERLAG - BERLIN

1968 
Erschienen im Akademie-Verlag GmbH, 100 Berlin, Leipziger SIrab 3-4 Copyright 1968 by Akademie-Vorlag GmbH Lizonznummer: $202 \cdot 100 / 492 / 68$

Gesamiherstellung: VEB Druckerai „Thomas MUntzer". 582 Bad Langensalza Bestallnummer: 3055/14 - ES 20 M B. 1 E

9,- 